\title{
What are the Ethics of Development Studies?
}

\section{Andrew Sumner}

\section{Introduction}

Development studies is an ethically complex field of enquiry. Consider for example the following:

- Development studies has an ethical or normative point of departure - it seeks change or to 'do good', thus it intervenes in the lives of others often claiming to know what is good for 'the Other'.

- Development studies involves work with research participants at completely different levels of social/economic/political/cultural power to the researcher

- Development studies addresses sensitive issues war, corruption, inequality, HIV/AIDS, poverty generally, to name but a few.

- Development studies is cross-cultural and crossdisciplinary - so whose ethics count? Do researchers give preference to universal principles (even if concepts such as the primacy of the individual are 'alien' concepts in the context in which they are working) or to local principles (even if contradictory to researcher's personal notions of social justice or equality)?

In spite of our growing awareness of this complexity, development studies as a field of enquiry has yet to explore fully many of the ethical dilemmas raised by doing research in developing countries. This is

surprising, perhaps, given that many researchers come to development studies with a strong sense of social justice and given the recent rise in interest in ethics in social science generally. That said, some constituent disciplines of development studies have been far more reflective than others. As Brown et al. (2004: 4) put it:

It is fair to say that there is a notable paucity of literature that deals specifically with the ethical dimensions of social science in developing contexts... Of the few disciplines to more directly reflect on these issues, anthropology has been engaged in sustained debate, especially since the early 1970s. With a few notable exceptions very little from within quantitative social science has been published on the ethical difficulties presented by the methodological complexities of underdeveloped regions since ... the early 1980s.

Often ethical dilemmas in research are 'sanitised' and rarely appear in final research outputs. However, it is not as if researchers in development studies are short of guidance. Development studies has a plethora of ethical guidelines to choose from: each constituent discipline in development studies can offer one. Most funders have one (take for example the UK Economic and Social Research Council), many universities have their own guidelines or committees by which research must be approved. But what about the ethics and perspectives of participants and the communities in which research is conducted? One issue is whether guidelines simply serve to protect the researcher from legal challenge rather than address deeper concerns about reciprocity, equitable relationships, and so on. Another is whether guidelines become straight-jackets for research, particularly the kinds of research that have become popular in development studies (notably, action or participatory research). $A$ further issue is that researchers may sign the ethical guidelines as required but may face real dilemmas when out 'in the field' confronted with the multiple ethical frameworks of different actors in the research process between whom there is ongoing negotiation.

Given the broad nature of ethics, what does this article seek to achieve? Section 2 discusses some points of departure on the question of what ethics are? Section 3 reflects on the ethical dimensions of the nature of development studies and Section 4 presents three ways in which researchers have thought about the ethics of development studies. 


\section{Box 1 Defining ethics}

- A system of moral principles: the ethics of a culture.

- The rules of conduct recognised in respect to a particular class of human actions or a particular group, culture, etc:: medical ethics; Christian ethics.

- Moral principles, as of an individual: his ethics forbade betrayal of a confidence.

- That branch of philosophy dealing with values relating to human conduct, with respect to the rightness and wrongness of certain actions and to the goodness and badness of the motives and ends of such actions.

Source dictionary.com (accessed 1 December 2006).

Finally, Section 5 presents some (tentative) conclusions about what researchers might do differently.

\section{What are ethics?}

The word 'ethics' comes from the Greek word ethos meaning character, custom or usage. There is, of course, an entire branch of philosophy dealing with ethics and the 'rightness' and 'wrongness' of actions. Ethics (see Box 1) is concerned with questions such as what should we do and how should we conduct ourselves. Ethical issues arise when researchers need to choose between courses of action not on the grounds of efficiency or expediency but what is 'morally' right or wrong.

But whose ethics do researchers abide by in their research? Denzin (1997) argues there are two models in social science. On the one hand, one might take the Kantian position - an absolutist or universal model - a set of principles with which there is no flexibility. Alternatively, one could adopt the postmodernist position of flexibility in ethical decisions and local meaning attached to the conceptualisation of ethics. It

\section{Figure 1 What is development studies?}

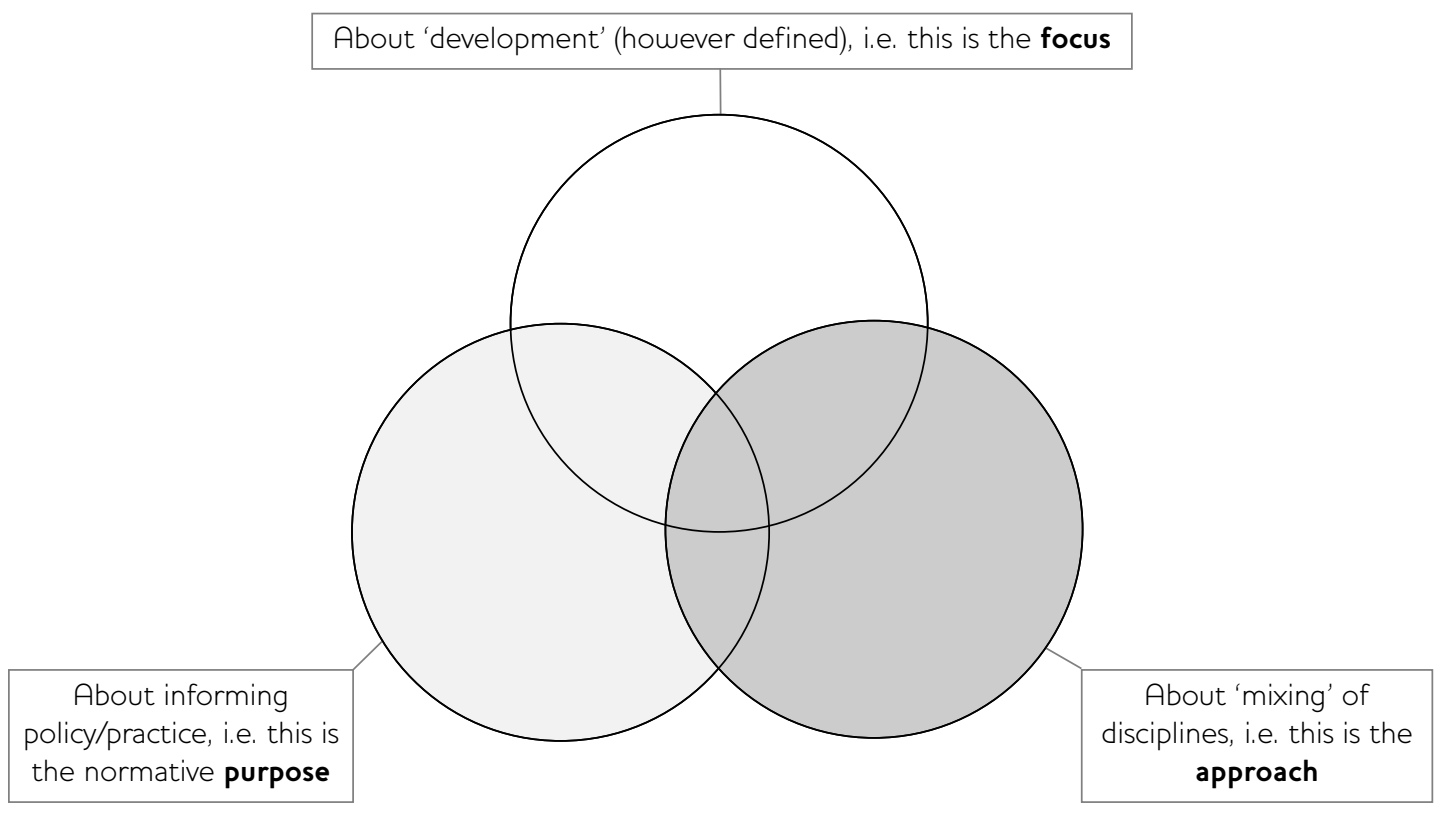


Table 1 What are the ethics of development studies?

\begin{tabular}{|c|c|}
\hline If development studies is... & Questions for researchers \\
\hline $\begin{array}{l}\text { about 'development' (however defined) } \\
\text { (i.e. the focus) }\end{array}$ & $\begin{array}{l}\text { Who decides what 'development' is and what to } \\
\text { research? }\end{array}$ \\
\hline about informing policy/practice (i.e. the aim) & $\begin{array}{l}\text { How can researchers seek to build non-hierarchical } \\
\text { relationships and/or recognise power in their }\end{array}$ \\
\hline \multirow{6}{*}{$\begin{array}{l}\text { Thus development studies 'intervenes' in the lives } \\
\text { of 'the Other' and deals with those at completely } \\
\text { different levels of social/economic/political/cultural } \\
\text { power }\end{array}$} & relationships with participants? \\
\hline & How do we do research that brings about change? \\
\hline & What do 'outsiders' bring to research? \\
\hline & What kind of relationships should researchers have \\
\hline & with the elite and policymakers we seek to influence? \\
\hline & What is the impact of research on non-participants? \\
\hline
\end{tabular}

about 'mixing' of disciplines (i.e. the approach)

Development studies is cross-cultural and cross-disciplinary - so whose ethics count?

Universal or local ethics? Which discipline's ethics? What about the ethical interfaces of social science and physical sciences? may be theoretically possible to resolve the tensions between the two extremes (universal vs. local) and tensions between disciplines within development studies through negotiation leading to what $\mathrm{Hølm}$ (2003) called a middle ground 'negotiated universalism'. How we actually do this in practice is a much more difficult question.

Aristotle, in the ten books of Nicomachean Ethics (350 BC), focused on the importance of being ethical or virtuous. For him the highest good was eudaimonia - happiness or having a good spirit or 'human flourishing'. He also believed that context was an essential factor. Is having (self-defined) 'good' intentions enough for development researchers? What role does context play in the ethics of development studies?

\section{What are the ethical questions arising from the nature of development studies?}

There is a growing literature on the question of the distinctive characteristics of development studies (see for example, DSA 2004; Harriss 2002; Hulme and Toye 2005; Loxley 2004; Molteberg and Bergstrøm 2002a, 2002b; Tribe and Sumner 2004). One might propose what is outlined in Figure 1 for discussion. This is not to say that all research in contemporary development studies fits this model but this is what many researchers in development studies are seeking. Development studies is about 'development' (however defined). Development studies is about informing policy and practice (i.e. to achieve development, however defined). Furthermore, development studies is about mixing disciplines (and linking different levels of analysis).

This raises all sorts of ethical questions (see Table 1). First, if development studies is about 'development', it is an ethical question who decides (or does not decide) what development is. Particularly because any definition frames who is 'in need' of development and makes assumptions about what should be done. This has been the main post-development critique of development studies: that it has often imposed its own (Western) ideas on 'the Other'. In development studies, the study of development has been about development in (what was) the 'Third World' but there is no reason why development studies might not encompass the 'First World' as well given that all countries are 'developing' in some sense. Further, the focus has not only been on 'poor' countries (however defined), but within those countries attention has been on 'the poor' and 'the marginalised', i.e. on 'them'. But we also need to ask: what about 'us', and 'the rich' or 'the powerful'?

Second, if development studies is about informing policy and practice (i.e. development studies' normative point of departure - an interest in knowledge-generation not for its own sake but for 
its instrumental use) this is an ethical consideration. Not least because it inevitably entails intervening in the lives of 'the Other' (those at completely different levels of social/economic/political/cultural power to the researcher).

Most are attracted to development studies by some sense of concern about social justice or prevailing levels of global poverty and inequality. Much development research now seeks to influence practitioners and in particular policymakers and/or elites. However, this normative aspect of development studies has only recently become recognised as ethically complex. As Mehta et al. (2006: 1) note:

research on development is normative, engaged, and seeks to make a difference. This makes it even more loaded and contested than other kinds of research.

In the past, development studies has faced sustained criticism from 'post-development theory' and 'postcolonial theory'. Drawing on Foucault, writers have argued that 'development' (read development studies) is a 'discourse' created by the 'West' which subjugates the 'Third World'. It does this through representing 'the Other' in a certain way. Development studies is in itself the problem (or at least part of the problem) because it presents a Western view of development as modernity that is then imposed on the Third World. Postdevelopment theory argues emancipation of Third World 'majorities' (the marginalised and poor) is best left to social movements that originate in those majorities, and therefore there is no role for development studies unless it emerges from those social movements. The overriding theme for postdevelopment is that 'outsiders' can never 'know' in an absolute or objective sense (i.e. to 'know' anything is a subjective experience):

Who are we - who am I - to intervene in other people's lives when we know so little about any life, including our own? (Rahnema 1997: 395)

Rahnema explored ways in which people become involved and do 'get to know' (albeit it in subjective ways), but stresses the importance of researchers reflecting on their own position and questioning their own 'knowledge'. Kapoor (2002) has argued too, drawing on Said's concept of Orientalism, that Western political-intellectual representations of the
Third World have been integral to subordinating the Third World

In short, 'the Orient' is synonymous with all Third World or non-Western societies. For post-colonial and indeed post-development writers, the concern is that intellectuals and development workers may be complicit in neocolonial knowledge production, or worse their practices may silence the Third World 'subaltern' (marginalised people). Spivak (1988) argued that when researchers 'represent the Other' they fail to recognise their own role in shaping that representation.

In other words, the representations we see as development researchers are a function of our 'positioning'. If researchers do not reflect openly on their positioning they run the risk of missing the point that researchers themselves (and power, gender, class, age and race and so on) shape the whole research process, the knowledge created and the use of that knowledge. However, if researchers reflect on their positioning too openly they leave themselves open to those who would question the rigour and validity of their research (and in particular its publishability). This is a difficult dilemma to overcome, and might be dealt with differently depending on what is being written and for whom. In a $\mathrm{PhD}$ thesis, for example, reflection is a vital part of the process of learning to research, but the readers of a policy document are unlikely to be interested in the author's ethical dilemmas.

Third, if development studies is about mixing approaches, what ethical issues does this raise? Most of those involved in development studies would probably not regard this as a discipline itself but an 'umbrella' area of study, covering a range of disciplines. Typically, development studies is thought to be some combination of social science disciplines, which might include economics, sociology, anthropology and politics, plus human geography and perhaps philosophy and psychology too (Hulme and Toye 2005: 3; Jackson 2002: 499; Kanbur 2002: 1). However, given that development studies is centrally concerned with the poor, the overwhelming number of whom live in rural areas, work in agriculture, and are dependent on natural resources, physical sciences are clearly of importance (Molteberg and Bergstrøm 2002a, 2002b; Morton and Martin 2004). Molteberg and Bergstrøm (2002a: 25) go so far as to argue development studies is defined by the fact that it: 
Figure 2 What are the ethics of development studies?

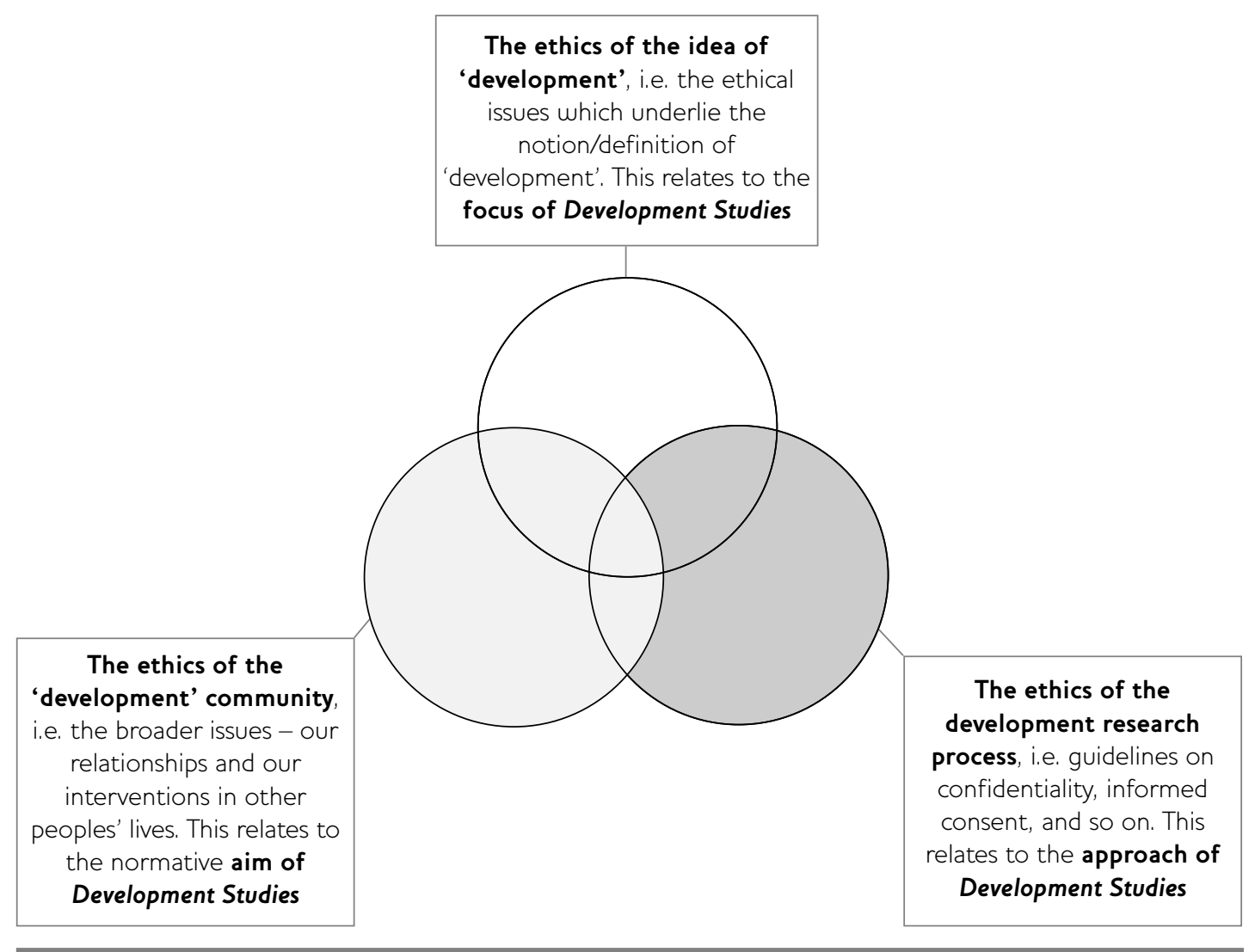

addresses complex problems at the nature-society interface and thus has to deal with issues in which phenomena of different ontological status are interlinked.

What about the ethical issues of combining different disciplines? One might think of how the ethical approaches of anthropologists and economists differ, particularly given that many economists see themselves as objective and thus it is not possible to misrepresent the 'Other'. In fact for some economists there is no 'Other' - there is only homo economicus. Further, context or local ethics may be perceived as having limited meaning in a universal, positivistic approach.

\section{Three ways of thinking about the ethics of development studies}

One might think of the ethics of development studies in at least three overlapping ways (see
Figure 2), each relating to the dimensions of 'what is development studies' previously identified.

The ethics of the very notion of 'development' are the same ethical issues which relate to defining human wellbeing or what is development (cf. Gaspar, Sen, etc.). As Kanbur (2006: 5) put it, any definition of development is dependent on 'values and on alternative conceptions of the good life'. Essentially, in this approach development ethics has become a critique of mainstream economics. This is how the International Development Ethics Association (IDEA) defines the 'ethics of development', as within the framework of the ethics of development 'goals' and 'strategies' (see Box 2). In short, the idea of development can be traced back to discussions of human wellbeing dating from antiquity.

The second approach - which considers the ethics of the research process - tends to focus on how 


\section{Box 2 The International Development Ethics Association}

IDEA is a cross-cultural group of philosophers, social scientists, and practitioners who apply ethical reflection to global development goals and strategies and to North/South relations.

www.development-ethics.org

research guidelines define the ethics of development. This could be seen as a somewhat narrow list of technical but nevertheless important issues related to the research process itself reciprocity, anonymity, confidentiality, informed consent, safety, and so on (see chapters in Desai and Potter 2006; Laws et al. 2003; Mikkelsen 2005). The common ethical 'thought question' posed with regard to the research process itself is how would you feel about a close friend or family member taking part in this research?

There are various lists or guidelines for development studies to choose from (see Box 3), but only one set (to the author's knowledge) is specifically tailored for development research - and that is the guidelines of the Royal Geographic Society Developing Areas Research Group (DARG). The range of guidelines available to choose from raises a further dilemma: does one choose the guidelines that are most 'convenient' (the easiest to address in the chosen research) or a 'best fit', rather than those that address the ethical issues raised by the research more deeply.

It can be argued that research ethics guidelines mediate against certain types of research (participatory and action research in particular) by their implicit creation of distance between the researcher and participants - an 'ethical safety zone'. Guidelines may tend to favour research which is perceived to be objective (where the researcher and researched are separable) rather than subjective research (with 'fuzzy' demarcation between researcher and participants). Indeed, given that participatory and action research may be predicated on the non-separability of researcher and participants (the participants are themselves researchers), then the ethical guidelines would apply unambiguously to the participants of the study as well as those who are researchers by profession, making the feasibility of remaining within the guidelines much more difficult (and the imposition of the ethics of a UK university's ethics committee on a community in a developing country questionable). Many of the concerns contained within guidelines differ according to the context. Others are questionable given the level of inequality between researcher and participant - take for example the questions around obtaining or giving informed consent (which may differ in meaning in different contexts).

The DARG guidelines were accepted at their AGM in 2003 in London. There is a set of 'Broad Principles' which are followed by a number of specifics relating to numerous issues (see Box 4). As the only set of development-relevant guidelines, they provide a point of reference for development studies.

David and Sutton (2004) argue that ethics should be considered at all stages of the research process, starting with the question at the outset about what 'deserves' researching, to the conduct of research and the use of research findings. In sum, ethics is about the whole process not just data collection. Questions to ask include: whose problems are researched? Whose voice counts? Who controls the process? Who owns the output? Ultimately who benefits? As Scheyvens and Storey (2003: 234) argue:

\section{Box 3 Ethics guidelines of academic associations relevant to development studies}

Association of Social Anthropologists: www.anthropology.ac.uk/ethics2.html

Political Studies Association: www.psa.ac.uk/Publications/Professional_Conduct.htm

Social Research Association: www.the-sra.org.uk/index.htm

Developing Areas Research Group, Royal Geographic Society: www.gg.rhul.ac.uk/DARG/ethical.htm 


\section{Box 4 The DARG Guidelines}

Broad Principles: Members of DARG should endeavour to incorporate the following broad principles in their work in and on the developing world: honesty, integrity, sensitivity, equality, reciprocity, reflectivity, morality, contextuality, non-discriminatory, fairness, awareness, openness, altruism, justice, trust, respect, commitment.

Specifics: Permission; access, disclosure, consent; risks; confidentiality, anonymity; privacy, intrusion; awareness; contextuality; reciprocity and partnerships; discrimination and exploitation; gifts, bribes, corruption; honesty, realism; power, responsibility; altruism, priority; positioning; outcomes; authentication; ownership; non-academic contexts; consultancy; distasteful organisations; government; professional reputation.

ethics goes beyond ... regulations to the very heart of appropriate conduct and respect for the norms and values of other people.

This brings us to the third way of seeing the ethics of development studies. This might be characterised as the community-wide issues - i.e. the ethics of the development community itself. This perspective reflects many of the issues which emerged during the IDS40 Roundtable discussions (see Table 2 which draws on the overview article by Haddad, this IDS Bulletin). For each point raised, questions for development researchers can be outlined. These questions are principally about the role of the researcher in international development. In particular, what responsibilities and accountabilities do researchers have for their work? What is/should be the role of the researcher? If development studies is predicated on a normative point of departure, do researchers have a responsibility for catalysing 'good change'? One might argue researchers have a strong responsibility for the impact of their research and 'good change'. Indeed, one might add that spending money on development research may be about increasing the knowledge base, but it could equally be argued that spending on research is implicitly predicated on the idea that the returns from development research are higher than the alternative uses of those funds for poverty reduction. To put it crudely, which has more impact - a dollar spent on development research or a dollar cash transfer to the poor and marginalised?

The debate seems to go to the heart of development studies. It is about the ethics of being a development researcher - i.e. the ethics of intervening in the lives of others based on the assumption that research can make a positive difference.

\section{What to do differently?}

So, what should researchers do differently? Two interrelated issues present themselves (and much of the following discussion is probably not new to many development researchers). First, reflecting more openly about our ethical dilemmas rather than 'sanitising' our research for publication. This would entail greater openness in reflecting on our positionality, explicitly situating ourselves in the research and being transparent about possible conflicts of interest between participants, funders and collaborators, and about our 'baggage'. Here development studies can learn from anthropologists and sociologists in particular, who have questioned academic distance and authority (Mehta 2006: 3).

The merits of development studies and cross-cultural research - research which crosses the bounds of one's own culture, sex, class, and so on - lie in the diversity of perspectives it can present. The real issue is who speaks (or claims to speak) for whom? Escobar (1995) critiqued development studies for legitimising Western 'experts' and undermining local knowledge. However, there are different forms of 'representation'. Spivak (1988: 275-6) differentiates between two: 'speaking for' (i.e. political representation) and 'speaking about' (i.e. making a portrait). Perhaps there is also a third 'speaking with' (i.e. engaging in dialogue). For postcolonial writers, the aim is to write 'history from below' or for 'those most consistently exiled from episteme' (Kapoor 2002: 653; Spivak 1990: 102-3). This might be a fourth form of representation although it has overlap with the earlier forms.

Second, and strongly related, we need to think more about the impact of our 'intervention' in the lives of other people. One might note Lather's 'catalytic validity' of our research or 'the degree to which the 
Table 2 Ethical issues raised at the IDS40 Roundtables

\begin{tabular}{ll}
\hline Ethical issues raised & Questions for researchers \\
\hline The role of outsiders & $\begin{array}{l}\text { Do outsiders 'crowd out' or 'crowd in' local } \\
\text { researchers? }\end{array}$ \\
\hline Capacity & Does research 'build' capacity? Should it? \\
\hline Accountability & Who are researchers accountable too and how? \\
\hline Control of the research agenda & Who should they be accountable to and how? \\
\hline The role of Northern research institutions & Who controls the research agenda? Who should? \\
\hline Independence & $\begin{array}{l}\text { What is the role of Northern institutes? } \\
\text { Policy relevance }\end{array}$ \\
\hline $\begin{array}{l}\text { What should it be? } \\
\text { Are researchers independent? From who? How? }\end{array}$ \\
$\begin{array}{l}\text { Do researchers have a responsibility for catalytic } \\
\text { change? ls policy relevance the only channel? Is } \\
\text { development studies, as currently constituted, policy } \\
\text { relevant? What does policy relevant or catalytic } \\
\text { research look like? What kind of relationships should } \\
\text { researchers have with the elites and policymakers } \\
\text { they seek to influence? }\end{array}$
\end{tabular}

research process reorients, focuses, and energises participants towards knowing reality in order to transform it' (1988: 272).

This also entails thinking about our own accountability. Who should decide the research agenda? How? What kinds of collaboration models are non-hierarchical? How can we influence the powerful? What kind of research reduces (what kind of) poverty? What are the transmission channels between 'knowledge' and societal change?

Parfitt has argued that it is not inevitable that development studies should be an imperialist discourse. Certainly, one might note that celebrating severe deprivation as 'cultural autonomy' is not an 'ethically' superior position (cf. Foucault's performative contradiction - if we can only know reality through discourse how can we claim any one discourse is more valid than another?). Parfitt (2002: 6-7, 83) also provides a useful exploration of why development studies should exist. He argues that members of 'social minorities' (i.e. those with relatively more power) are ethically obliged to assist the 'social majorities' (i.e. those with less power). This draws heavily on the ethics of Emmanuel Levinas who argued that the question is not 'why do we exist?' but 'how do we justify our existence?'. Levinas contended that human beings have an infinite responsibility for 'the Other' because our own sense of identity is constructed from our 'position' regarding, and relationships with, other human beings. His central proposition was our relationship with 'the Other' forms our self-identity to a large measure. Indeed, human beings only have a sense of identity through the existence of others, thus we have a fundamental obligation to treat others well because we depend on them for our own sense of identity. Levinas' ethics thus provide a basis, but not an inevitable imperative for engaging in development because of its role in establishing our identity as a constituent element in universal human characteristics.

In sum, development studies raises a surprising depth of ethical complexity. It would seem researchers need some flexible, open, guiding principles rather than guidelines to frame research. Perhaps it is worth always bearing in mind the question: why am I or we - researcher(s) - here at all? What is the rationale for development studies to exist? If development research is not part of catalytic change in some form, what ethical basis is there for its existence? All of the above raises the issue of the relationships researchers form with not only participants in their research but with their collaborators and funders, or policymakers and elites. The issues extend into the accountability of researchers (to whom? how?) and the independence 
of researchers (of whom? how?) and the ownership of research (who should decide the agenda? how?).

These are big questions with no easy answers. What could researchers do more immediately? Thinking of guiding principles rather than guidelines, Pham and Jones (2006: 2-3, 5) propose four dimensions of social-justice related research as follows:

[The four dimensions are] self-reflexivity in the research process; reciprocity dialogue with

\section{Acknowledgement}

For comments on earlier versions of this article the author would like to thank Andrew Crabtree, Allister McGregor, Lyla Mehta, Sara Parker, Alan Thomas and Michael Tribe.

\section{References}

Brown, N., Boulton, M. and Webster, A. (2004) Social Science Research Ethics in Developing Countries and Contexts: ESRC Research Ethics Framework, Discussion Paper 3, York: ESRC Research Ethics Framework Project, Science and Technology Studies Unit, Department of Sociology, University of York and Oxford: School of Social Studies and Law, Oxford Brookes University

David, M. and Sutton, C. (2004) Social Research: The Basics, London: Sage

Denzin, Norman K. (1997) Interpretative Ethnography: Ethnographic Practices for the 21st Century, London: Sage Publications

Desai, V. and Potter, R. (2006) Doing Development Research, London: Sage

DSA (2004) Unit of Assessment in the Research Assessment Exercise 2008 for Development Studies, Development Studies Association, www.devstud.org.uk/consultation.htm (accessed 1 August 2005)

Escobar, A. (1995) Encountering Development: The Making and Unmaking of the Third World, Princeton: Princeton University Press

Harriss, J. (2002) 'The Case for Cross-Disciplinary Approaches in International Development', World Development 30.12: 487-96

Hølm, Soren (2003) 'Moral Pluralism', in 'The Ethical Aspects of Biomedical Researching Developing Countries', Proceedings of a Roundtable (1 October 2002), Luxembourg: Luxembourg research participants; uncovering marginalised knowledges; and rethinking definitions of research design and validity...

In short, development studies is about action (seeking to understand and analyse action) and for action (aiming to inform action or to be a form of action, for example through social experimentation and learning). As Pham and Jones go on to cite, Lather's test is central - the extent to which research is a catalyst for transformation seems to me to be crucial.
Office for Official Publications of the European Communities

Hulme, D. and Toye, J. (2005) The Case for Crossdisciplinary Social Science Research on Poverty, Inequality and Well-being, GPRG Working Paper 1, IDPM (Institute for Development Policy and Management) and CSAE (Centre for the Study of African Economies): Manchester and Oxford, http://gprg.econ.ox.ac.uk/pubs/ workingpapers/ (accessed 1 August 2005)

Jackson, C. (2002) 'Disciplining Gender?', World Development 30.3: 497-509

Kanbur, R. (2006) What's Social Policy Got To Do With Economic Growth?, Cornell University Working Paper, www.arts.cornell.edu/poverty/kanbur/ (accessed 1 August 2005)

Kanbur, R. (2002) 'Economics, Social Science and Development', World Development 30.3: 477-86

Kapoor, I. (2002) 'Capitalism, Culture, Agency: Dependency Versus Postcolonial Theory', Third World Quarterly 23.4: 647-64

Lather, P. (1988) 'Feminist Perspectives on Empowering Research Methodologies', Women's Studies International Forum 11.6: 569-81

Laws, S., Harper, C. and Marcus, R. (2003) Research for Development: A Practical Guide, London: Sage

Loxley, J. (2004) 'What is Distinctive About International Development Studies?', Canadian Journal of Development Studies 25.1: 25-38

Mehta, L. (2006) Somewhere Over the Rainbow? The Politics and Dilemmas of Researching Citizenship and Marginality, Brighton: IDS 
Mehta, L., Haug, R. and Haddad, L. (2006) 'Reinventing Development Research', Forum for Development Studies 33.1

Mikkelsen, B. (2005) Methods for Development Work and Research, second edition, London: Sage

Molteberg, E. and Bergström, C. (2002a) Our Common Discourse: Diversity and Paradigms in Development Studies, Working Paper 20, Ås, Norway: NORAGRIC

Molteberg, E. and Bergström, C. (2002b) Our Common Discourse: Diversity and Paradigms in Development Studies, Working Paper 21, Ås, Norway: NORAGRIC

Morton, J. and Martin, A. (2004) 'Natural Resources Research and Development Studies', paper prepared for DSA Annual Conference, Church House, London, 6 November

Parfitt, T. (2002) The End of Development? Modernity, Post-Modernity and Development, London: Pluto

Pham, Thi Lan and Jones, N. (2006) The Ethics of Research Reciprocity: Making Children's Voices Heard in Poverty Reduction Policymaking in Viet Nam, Young Lives Working Paper, London: Save the Children

Rahnema, M. (1997) 'Towards Post-Development: Searching for Signposts, a New Language and New Paradigms', in M. Rahnema and V. Bawtree (eds), The Post-Development Reader, London: Zed Books

Rahnema, M. (1992) 'Poverty', in W. Sachs (ed.), The Development Dictionary, London: Zed Books Scheyvens, R. and Storey, D. (2003) Development Fieldwork: A Practical Guide, London: Sage

Spivak, G. (1990) 'Poststructuralism, Marginality, Post-coloniality and Value', in P. Collie and H. Greyer-Ryan (eds), Literary Theory Today, London: Polity

Spivak, G. (1988) In Other Worlds, New York: Routledge Tribe, M. and Sumner, A. (2004) 'The Nature of Development Studies', paper prepared for DSA Annual Conference, Church House, London, 6 November 